\title{
Enhancing Lexical Knowledge through L2 Medium Tasks
}

\author{
Marjan Vosoughi ${ }^{1}$ \\ ${ }^{1}$ English department, Sabzevar branch, Islamic Azad University, Sabzevar, Iran \\ Correspondence: Marjan Vosoughi, English department, Sabzevar branch, Islamic Azad University, Sabzevar, \\ Iran. Tel: 98-915-371-6935. E-mail: Vosoughee@iaus.ac.ir
}

Received: July 19, $2012 \quad$ Accepted: August 3, $2012 \quad$ Online Published: August 16, 2012
doi:10.5539/elt.v5n10p34 URL: http://dx.doi.org/10.5539/elt.v5n10p34

\begin{abstract}
The purpose of the present study was to investigate the L2 use rate in EFL classrooms through introducing three task conditions in learning lexical items. Date were collected from a group of freshman university students (male and female) studying in Islamic Azad university of Sabzevar, Iran. (N=73). Based on their performance on a Michigan TOEFL reading test battery, they were first randomly divided into three groups, each completing one of the three vocabulary learning tasks that varied in the amount of L1/L2 use they induced during a two month period. The tasks were 'Reading plus further L2 reading', 'Reading plus L1 translation only' and 'dictionary work'. The statistical analysis of the students' performance on vocabulary post-tests was performed through One-Way ANOVA followed with the post hoc Regression Scheffe test to analyze which task has created a meaningful mean variability at $0 / 05$ for both between and within groups. The results showed the outperformance of the group receiving 'reading plus further L2 reading' tasks and not the tasks involving more L1 use. $(\mathrm{p}:<0.05)$ Possible implications of the study are presented in the light of Task Load Involvement Hypothesis by (Laufer \& Hulstijn, 2001).
\end{abstract}

Keywords: language tasks, vocabulary learning, L2 medium, involvement load hypothesis, L1 word equivalent, input saliency, recall

\section{Introduction}

In EFL settings where the learners are engaged in learning thousands of new words, teachers might be very much interested in the proper ways to maximize the learners' vocabulary knowledge. This matter gets even more important when various recent research projects focus specifically on the direct relationship of the learners' lexical knowledge and EFL success esp., reading comprehension skills, the one most important skill among the three other skills of writing, speaking \& listening. (Decarrico, 2001; Poulisse \& Schils, 1995; Lawson \& Hogben, 1996). The emphasis on lexical item even sometimes extends to the whole success evaluation in learning another language. Zimmerman, (1997) asserts, "vocabulary is central to language and of critical importance to the typical language learner." In other words, we may even go so far as to say that maximizing vocabulary knowledge range is central to language acquisition whether the language is first, second or foreign.

\subsection{Context of the Problem}

In Iranian educational centers where uni-skill language processing is current, reading passages are rather long containing approximately 600-800 words each thus needing previous elaboration techniques by the teachers. In each lesson, 10-15 new words are introduced initially. Unfortunately the time normally allocated to teaching this part of the lesson hardly reaches more than 20 minutes or so. Hence, a suitable way of presenting vocabulary in EFL classes is of major importance to learners. In fact, more elaboration techniques must be manipulated by the teachers since the direct connection of lexical knowledge and better reading comprehension has been vigorously confirmed in other recent research experiments too." (Hunt, Belgar 2005: 24 \& Zimmerman 1997: 5).

\subsection{The Significance of the Study}

A huge bulk of research data on lexical knowledge involvement is concerned with incidental vocabulary learning. In the present research, a special attention is paid to involving the learners in their routine classroom situations at which the specified tasks are deliberately incorporated to maximize their lexical knowledge for their intentional English words.

It's true that designing appropriate tasks by the teachers seems to be one of the effective measures to be done by 
the language teachers; however, in reality much gets neglected by many EFL teachers and mostly the same reutilized classroom activities are followed like fill in the blanks and matching items and even worse mostly through the medium of L1. Christensen (2007) (cited in Mehrabi 2011) claimed that a great deal of second language vocabulary can be learned through reading, but at the same time he refers to the "beginner's paradox" by raising doubts about the ability of beginners to learn vocabulary through extensive reading when they do not know enough words to read well. Thus, in the present study, an attempt was made to scrutinize the issue more by applying three different tasks each various with the range of L1 use they provoked.

\subsection{The Research Questions}

Thus, the proposed questions were:

1. Can task inducement through L1 medium help EFL learners to learn intentional vocabulary items?

2. What mechanisms are involved in promoting lexical knowledge among EFL learners through the medium of instruction?

\section{Review of Related Literature}

In order to cater for the complexity of relationship between vocabulary knowledge and language acquisition, various hypotheses have been recently developed. 'Instrumentalist Hypothesis' is just one proposed theory indicating the connection between vocabulary knowledge and a better reading comprehension (Beck \& McKeown, 1991).

(Mezynski, 1983) elaborates on the gist of still another theory called 'access hypothesis' to elaborate on the best use of word knowledge in reading comprehension, students should have a quick and easy access to the words they already know. 'Depth of processing' theory by (Craik \& Lockhart, 1972) was also another premise in teaching vocabulary indicating the due inherent effect of instructing vocabulary through elaborating words in deep. The intention was that the more deeply we process information, the better it is retained. Here, time spent on task is considered less important than the deep/shallow processing level. Processing the meaning of a new word, for instance, is worked on a rather deeper level than working on the phonological realization of those new words.

Laufer \& Hulstijn (2001) offered a controversial hypothesis named 'Task-induced Involvement Load Hypothesis' (TILH) which is currently very much cited by the TESOL investigators. The TILH decomposes the active mental processes involved in vocabulary learning into three cognitive components (search, evaluation) and a motivational (need) component. This hypothesis has been further elaborated later in this research.

Selection and proper application of tasks as (Richards \& Rodgers, 2001; Ellis, 2003 \& Nunan, 2005) believe involve specific constituents such as goal setting, procedure and specific outcome and it supports content-oriented meaningful activities rather than linguistic forms (Beglar \& Hunt, 2002; Littlewood, 2004 cited in Murat \& Sibel Hismanoglu, 2011). This point i.e. using content-oriented task types is of paramount importance here.

Unfortunately, Iranian EFL teachers put much focus on forms and getting the right specified answer is called for by the students in their task completions. This is important because the type of discourse emerging from tasks is aimed to be similar to the natural setting in the real world (Ellis, 2000). Cummins (2005) describes monolingual approaches towards Language Learning effective on the grounds that they encourage translation in L2 as a reversion towards discrete grammar translation methodologies so common in EFL situation. He talks of two solitudes for the two L1 vs. L2 identities. Along the same lines, other scholars had also termed similar terminologies in the past like Heller's (1999) 'parallel monolingualism', Swain's (1983) 'bilingualism through monolingualism'. With the advent of communicative language teaching approaches in 1980s such notions were vigorously followed by the experts in the field.

\subsection{Recent Proponents for L1 Use in Language Class}

No doubt, L1 use in English teaching classrooms was seriously frowned upon by the English teachers. However, quite recently EFL researchers are trying to find a balance and seek for a more flexible approach for both L1 vs. L2 use in language classrooms. (Anderson, 2008; Arthur \& Martin, 2006) are just some examples. They all seem to have argued for more multilingual pedagogic and curriculum research studies that favor the use of learners' L1 in class. They all go for increasing the L1 use with the purpose of promoting learners' participation in the learning processes and developing less formal relationships among participants. They give huge mottos for the pedagogic validity of 'code switching' (Arthur \& Martin, 2006: 197). 
In Iran, there have also been recently some grounds for accelerating more L1 use in the English classrooms specifically for lower level learners. Among some, we can refer to (Mehrabi, 2011) who introduces 'diglot weave' technique in his study denoting the use of an L2 word via an L1 utterance. (كار heart در body (Kare heart Dar body Ensan Chist?) He describes all features of this so-called technique and claims that it can build comprehension and increase confidence and enthusiasm among the learners. Although he concludes applying such techniques might help the learners eradicate anxiety factors, care must be taken not to overextend the use of L1 over L2. As (Jingxia, 2008) asserts, it is hard to decide on a fixed criterion on the amount of L1 use, but teachers need to consider lesson contents to make a judicious and principled decision on how much L1 will best suit students' needs in different contexts and this way they might avoid the overuse of the L1. In another study by (Hayati \& Mohammadi, 2009), the effects of task-based activities versus translation for incidental learning of vocabulary were handled. Their results surprisingly demonstrated that the group being involved in the translation activity was better. They concluded that in EFL contexts, using translation in a communicative framework enhances vocabulary learning at deeper levels of cognitive processing thus leading to deeper vocabulary gains for unknown words." (p. 153). In those studies working on incidental vocabulary exposures, it was emphasized that words learnt through reading tasks were remembered better than those received through synonym presentation techniques. Words that were looked up in the dictionary by the learners were remembered better than the words learned through marginal glosses in the texts. (Hulstijin, 1992 \& 2001).

\section{Method}

This study followed an experimental design (within group) working among some 73 Iranian university students whose bilingual lexical knowledge was targeted in three different contexts that the teacher provoked intentionally to cater for the due effect of three different Task inducement activities concerning the ratio of medium of instruction in L1 vs. L2.

\subsection{Participants}

For the first phase of the study, 73 learners were selected from among 80 Freshman University (both male and female) students who had taken a pre-university English course in Islamic Azad university of Sabzevar, Iran. Their major was Electronics and they were studying at BA level. Their age range was 20-25. The selection procedure was done on their performance on a Validated Michigan TOEFL test. For pheasibility purposes, just vocabulary and structure section of the whole battery test were given to the students. Since most of them had scored less than 33.33 on their entrance examination, the reading section of the TOEFL test battery wasn't given to them. The present study was done in the learners' reutilized classroom time during approximately a ten-week period of their whole second semester in Feb-Apr., 2012. Since each week two hours of class period was allocated to pre-university courses, the researcher couldn't increase the time interval for task treatments.

\subsection{Materials}

The book chosen for instruction was the best selling International 'Reading and vocabulary development' series (4th Edition, vol. 1) entitled as 'Facts and figures' by Patricia Ackert \& Linda Lee. (2005). This series has been designed for the students of English as a second or foreign language who have a basic vocabulary of about 300 words. The reason behind choosing this book for instruction was its unique features as to providing a theme-based approach to reading comprehension skills which is effective for Persian native speakers who are studying in EFL settings like Iran. In each unit, a theme is introduced such as animals, plants or occupations. One of the primary tasks for beginning students is developing a useful and personally relevant vocabulary base. In each lesson, up to 12 words are introduced. A list of 60 words were assigned for instruction from the first 5 lessons in unit 1 of the book and then given to the learners at the beginning of the term to verify which words students knew already. They were asked to write a Persian equivalent for the words they knew. Enumerating the known-unknown words, about 10 words receiving the most correct scores by the learners were deleted from the list in the final post tests and the immediate attention by the instructor.

\subsection{Procedure}

The students took part in a ten- week period of their normal English class time in a semester. Experiments were performed by the same teacher for three homogenious classes in blind. All the necessary instruction on the task application was given to the instructor. Three tasks were selected for vocabulary instruction enhancement. The intention behind each task inducement was evaluating the degree to which the learners are exposed to L2 vs. their L1 lexical equivalents and verifying the due effect on the learners' retention of intentional vocabulary. Time on task for each group was 60-70 ( $\mathrm{min}),(40-55),(30-35)$ respectively. Since the researcher liked to partially replicate Laufers' study, different time on tasks were elaborated since here also time on task was one of the 
inherent features of the three various tasks that could possibly lead to more success. So, we didn't keep time on task identical on applying the three task conditions.

\subsubsection{The Assigned Task Conditions}

The first task was 'Reading plus further reading'. In this activity, after finishing the text the new words in the lesson were further practiced by the learners being exposed to another text having similarly the same content. The texts were retrieved by the teacher on the internet from various websites and further explored by the students with the teachers' supervision. Meanwhile no Persian equivalent was given to the learners. All new words appeared in new contexts over and over again. The teacher clarified the meaning of other unknown words through the medium of English only. A list of communicative exercises for comprehension check in post-reading parts of the lesson were followed by the teachers and students in each session without specific focus over the intended words in the text. The second task was given to the second group entitled as 'Dictionary work'. Here, the learners were asked to make a dictionary out of the new words in each lesson after the text was finished. The learners were asked to write:

A: An English equivalent plus another example featuring the new word from the dictionary;

B: its synonym(s) and

C: its pronunciation.

Some very difficult words were described and elaborated through Persian as the last resort. The task chosen for the third group was 'L1 translation production only'. After being exposed to the text, the learners were required to provide an L1 equivalent for the new words. The reutilized fill in the blanks and matching items were followed thoroughly in each lesson. All the exercises were translated to Persian by the teacher. The difference between the second task treatment and the third was that in the former all the learners were actively involved in planning and organizing their learnt materials while in the latter just the teacher was responsible for L1 production of unknown words. There was a one week interval between the sessions for each group.

\section{Results}

After going through the whole process of task inducement procedures for the three groups over the 10-week period, the same 50-item test was given to the learners without requiring them to study beforehand. Since the intention was to check the status of intentional vocabulary, just those selected vocabulary items mentioned above were included in the post test. Since more than two means were involved, a repeated measure of one-way ANOVA (3*3) analysis of variance was performed through SPSS Software ver. 15. The results showed a significant mean difference among the means at $0 / 05$. ( $\mathrm{p}$ value: $0 / 000<0.05$ ). This let us reject the null hypothesis as to there is no difference for the effect of three task conditions involved. (Table 1)

Table 1. One-way ANOVA for between and within group comparisons of the means in the post test

\section{ANOVA}

scores

\begin{tabular}{llllll}
\hline & & & \multicolumn{3}{c}{ Sum of } \\
Sig. & F & Mean Square & df & Squares & \\
\hline .000 & 14.474 & 338.881 & 2 & 677.762 & Between Groups \\
& & 23.414 & 70 & 1638.958 & Within Groups \\
& & 72 & 2316.719 & Total \\
\hline
\end{tabular}

\subsection{Data Analysis}

To scrutinize which mean for the task involvement conditions was significantly more effective compared with the other two tasks, the post hoc Regression Scheffe test was applied further at p: $<0 / 05$ for both between and within groups. The results showed the outperformance of the group receiving 'Reading plus further L2 reading' tasks. (Table 2) 
Table 2. The scheffe post hoc test for multiple comparisons among the three task groups

\section{Multiple Comparisons}

Dependent Variable: marks

Scheffe

\begin{tabular}{lllllll}
\hline & & & & Mean \\
95\% Confidence Interval & Sig. & Std. Error & Difference $(\mathrm{I}-\mathrm{J})$ & $(\mathrm{J})$ task treatment & $(\mathrm{I})$ task treatment \\
\hline Lower & & Lower & & Lower & & \\
Bound & Upper Bound & Bound & Upper Bound & Bound & & \\
\hline-1.6234 & -8.5100 & .002 & 1.37673 & $-5.06667\left(^{*}\right)$ & further reading & dictionary work \\
5.5557 & -1.8285 & .455 & 1.47621 & 1.86364 & L1 translation & \\
8.5100 & 1.6234 & .002 & 1.37673 & $5.06667\left(^{*}\right)$ & dictionary work & further reading \\
10.3273 & 3.5333 & .000 & 1.35820 & $6.93030\left(^{*}\right)$ & L1 translation & \\
1.8285 & -5.5557 & .455 & 1.47621 & -1.86364 & dictionary work & L1 translation \\
-3.5333 & -10.3273 & .000 & 1.35820 & $-6.93030\left(^{*}\right)$ & further reading & \\
\hline
\end{tabular}

* The mean difference is significant at the .05 level.

The results clearly were evidence for the outperformance of the group receiving more input in L2 compared with the other L1-induced task group types contrary to those recent translanguaging movements.

If we consider the following homogeneous subtests for the data in table 3 below, we can see the results indicating the fact that the means for the tasks 'dictionary work' \& 'L1 translation production only' have been centered in one column showing the $\mathrm{p}$ value equal to 0.419 at $0 / 05$ significance level thus a clue for their variable outcomes on the one hand and their significant lower result compared with 'reading plus further L2 reading' task on the other. However the interesting finding here observed was that between the two task groups of 'L1 translation production only' \& 'dictionary work', a higher mean of $(\mu=15.500)$ was observed for the group receiving 'Dictionary work' task' compared with 'L1 translation productin only' task group ( $\mu=13.6364)$. Thus the former group who had received dictionary work task performed better than the group receiving L1 translation productin only tasks. (See Figure 1) This was interesting in the light of (Laufer and Hulstijn, 2001) Task-Load Involvement Hypothesis which is discussed in the next section.

Table 3. Cross-result subsets for mean variances in various task conditions

\section{Scores}

Scheffe

\begin{tabular}{llll}
\hline \multicolumn{2}{l}{ Subset for alpha $=.05$} & $\mathrm{~N}$ & task treatment \\
\hline 1 & 2 & 1 & \\
\hline & 13.6364 & 22 & L1 translation \\
& 15.5000 & 21 & dictionary work \\
20.5667 & & 30 & further reading \\
1.000 & .419 & & Sig. \\
\hline
\end{tabular}




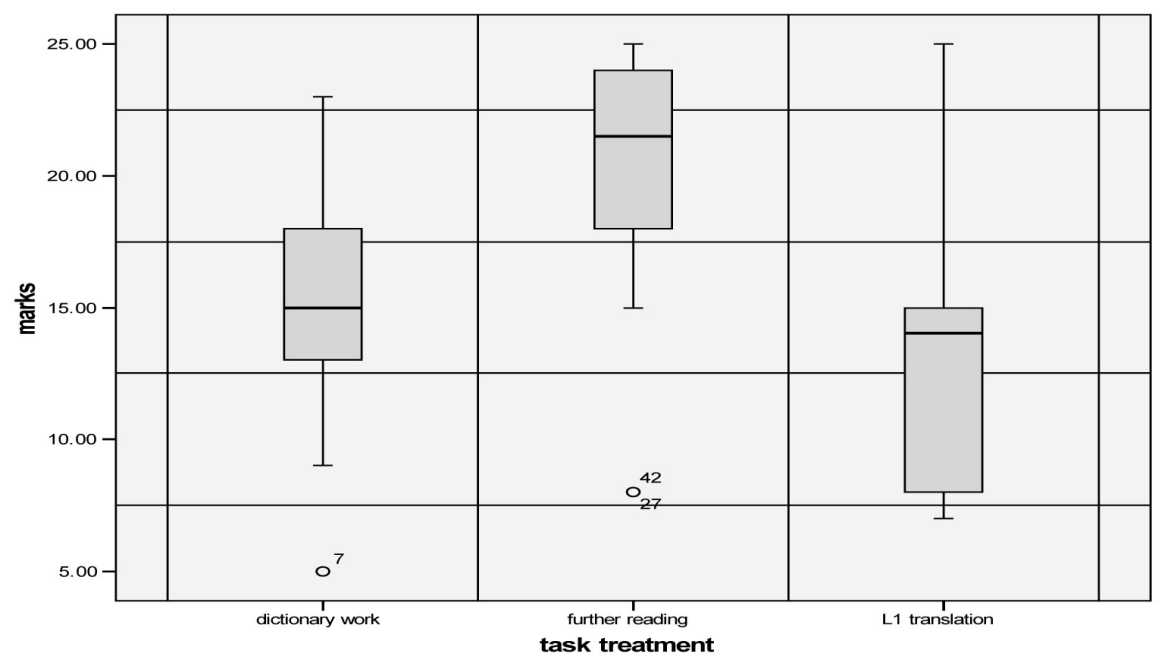

Figure 1. The box plot for three task treatment outcomes

\section{Discussion}

The present experimental research reported findings on an experiment over task inducement medium of instruction (L1 vs. L2) on the promotion of lexical knowledge conducted among some EFL Iranian learners with Persian as L1 (first language) and English as the FL (foreign language). The main intention behind using the introduced tasks was to compare the degree to which they could engage the learners in activating their lexical knowledge via L1 vs. L2 medium. Going through statistical measurements, the group receiving the tasks through only the L2 input could significantly gain better results in the post tests compared with the other two groups.

This short survey tried to prove the impact for Lack of exposure to enough language input through task-induced elaboration techniques without $\mathrm{L} 1 \mathrm{use}$ to test their due effects in intentional vocabulary instruction.

If we inspect vocabulary instruction sessions in our country, the 10 year experience of the researcher in Iranian EFL settings reveals that a false circuit exists; promoting vocabulary for reading expansion and on the other hand misapplying the techniques that lead to both poor reading and vocabulary knowledge fade among the puzzled learners. Instruction in vocabulary as we must note involves far more than looking up words in a dictionary and using the words in a sentence. Although one mustn't doubt the fact that dictionary use teaches students about multiple word meanings, as well as the importance of choosing the appropriate definition to fit the particular context, contextual analysis involves inferring the meaning of an unfamiliar word by scrutinizing the text surrounding it. Such multiple exposures to the L2 input brings about word saliency ie, consolidating word knowledge and bringing the lexical components of unfamiliar words to the learners' immediate attention and more recall. The element of attention is responsible for such saliency. Seeing the words in multiple contexts according to (Stahle, 2005, cited in Diamond, L. \& Gutlohn, L. 2006) places them firmly in their long-term memory. Thus giving the students those opportunities that foster multiple exposures fosters their lexical knowledge better than repetitious reutilized drills much used by the EFL teachers in Iran.

Generally speaking, Vocabulary is acquired incidentally through indirect exposure to words and intentionally through explicit instruction in specific words and word-learning strategies. According to (Michael Graves, 2000, cited in Linda Diamond and Linda Gutlohn, 2006), there are four components for an effective vocabulary program:

1. wide or extensive independent reading to expand word knowledge

2. instruction in specific words to enhance comprehension of texts containing those words

3. instruction in independent word-learning strategies, and

4. word consciousness and word-play activities to motivate and enhance learning

At this point, it's good to reiterate the outperformance of the group receiving 'dictionary work' over 'L1 translation production only' to account for the further proving of the seminal Task Load Involvement Hypothesis by Laufer and Hulstijn (2001). Their theory attempted to operationalise task based involvement through 
assessing three factors; Need, Search and Evaluation. To account for the ideas mentioned by the proponents of Task Load Involvement or similar other earlier theories like depth of processing by (Craik \& Lockhart, 1972) and Input Hypostasis by (Krashen, 1979), it's enough to say just the more effective tasks are those that require a deeper level of processing. However more interestingly over the other hypotheses, the Task Load Involvement permits the researchers to clearly estimate and objectively measure such so-called sense of 'depth'.

Thus far, for the mentioned tasks manipulated in this short survey, if we account for the criteria including the three elements of 'need', 'search' and 'evaluation', the following (Table 4) might clarify the issue why each task has created more achievements over the others.

The 'need' component is meant to be the motivational non-cognitive dimension of Involvement. The other two components 'Search' and 'evaluation' are cognitive based damnations depending upon the giving attention to form-meaning relationships. 'Evaluation' entails comparing words with other similar words. If such insights are just for the sake of recognizing the differences among words, it's called moderate. If decision must be made how additional words can be combined in the original sentence or context, it's termed as 'strong'. For the three tasks involved in the present study, overall calculation of task involvement index can be observed in Table 3. Although the researcher doesn't believe that there is a quite objective-based scale for predicting the success of one task over the other, just the degree of involvement that can be a good predictor of more retention regarding words could be estimated here. A word of caution thus for involvement index task 1 (index $=3$ ) compared with task 2 (index $=5$ ) since the results in this study indicated the outperformance of task 1 over the task 2 . However, the superiority of Task 2 over Task 3 can easily be verified by the Task Load Involvement. Overall, the hints worth mentioning here for the hidden reasons behind the outperformance of the 'Reading plus further reading' group over the other two can be enumerated as follows:

1. Learners received more exposures to unfamiliar terms in various contexts. (this aspects can be verified in the light of Input hypothesis by Krashen (1989)

2. Learners got familiar with the unknown words in their real uses.

3. Some previously learnt words were repeatedly displayed and thus were further consolidated. (The element of reinforcement via revisiting in vocabulary learning)

4. Learners were actively engaged in the learning process. (Learner participation was guaranteed)

5. Developing schematic knowledge among the learners via knowing unknown through known words. Scott (2005) termed this activity as 'developing a schema for unknown words'.

6. Wide reading activates the learners' deep insights on both word knowledge and world knowledge thus it builds on student interest and word awareness skills

7. Last but not least, since those words assigned for learning appeared intentionally in L2 discussions after the texts were finished, they were naturally revisited over and over again thus helping to their retention by the learners.

Table 4. Task-induced Load index for the three task conditions in the present study

\begin{tabular}{|c|c|c|c|c|}
\hline & Need & search & evaluation & $\begin{array}{l}\text { Involvement } \\
\text { Index }\end{array}$ \\
\hline $\begin{array}{l}\text { 'Reading plus further } \\
\text { reading' tasks } \\
\text { Time on task: } 60-70\end{array}$ & $\begin{array}{l}\text { Moderate (1) } \\
\text { Target words given } \\
\text { in margins } \\
\text { (glossed) }\end{array}$ & $\begin{array}{l}\text { Moderate (1) } \\
\text { The meanings were } \\
\text { manipulated through } \\
\text { L2 by the teacher } \\
\text { supervision only }\end{array}$ & $\begin{array}{l}\text { moderate (1) } \\
\text { Words were evaluated } \\
\text { in further contexts } \\
\text { provided by the } \\
\text { teacher }\end{array}$ & 3 \\
\hline $\begin{array}{l}\text { 'Dictionary } \quad \text { work' } \\
\text { Tasks } \\
\text { Time on task: } 40-55\end{array}$ & $\begin{array}{l}\text { Moderate (1) } \\
\text { Target words given } \\
\text { in } \quad \text { margins } \\
\text { (glossed) }\end{array}$ & $\begin{array}{l}\text { Strong( } 2) \\
\text { The meanings were } \\
\text { manipulated by the } \\
\text { students }\end{array}$ & $\begin{array}{l}\text { Strong (2) } \\
\text { Words were evaluated } \\
\text { in further example } \\
\text { sentences written by } \\
\text { the students }\end{array}$ & 5 \\
\hline $\begin{array}{l}\text { "L1 Translation } \\
\text { production only } \\
\text { tasks' } \\
\text { Time on task: } 30-35\end{array}$ & $\begin{array}{l}\text { Moderate (1) } \\
\text { Target words given } \\
\text { in margins } \\
\text { (glossed) }\end{array}$ & $\begin{array}{l}- \\
\text { The meanings were } \\
\text { provided by the } \\
\text { teacher }\end{array}$ & $\begin{array}{l}-\quad(0) \\
-\quad \text { Words were not } \\
\text { evaluated at all }\end{array}$ & 1 \\
\hline
\end{tabular}




\section{Possible Implications of the Study}

The pupose behind this small scale image of task inducement pedagogy was to consider multiple L2 exposures versus varying tasks to evaluate the degree to which L2 input inducement could estimate word retention among some Iranian EFL university students. As to the results the more L2 exposures, the more retention was gauged among the learners. This survey may be extended to other aspects of the whole language components and skills in EFL classrooms where the learners are deprived of the enough input in L2. In Iran, teaching and learning English is confronted with various problems and the reached outcomes thus far have not been satisfactory. After going through six or seven years learning English in high schools, the Iranian students can't use the language for its own purposes. Even at the surface level of the language they face lots of problems in both recognizing and producing structure, lexis and pronunciation let alone its communicative purposes.

The reasons have been extensively discussed by various researchers in the field as to the status of language teaching itself in Iran as a foreign language thus referring the problem back to the educational policy makers from above, on the one hand and the other factors including uninterested learners, implementing improper teaching techniques by incompetent teachers, limited audio-visual aids at schools, mandated testing programs, limited time and using problematic materials on the other. It seems that the above-mentioned reasons are all related to some controlled processes misapplied by both higher educational authorities including policy makers and curriculum designers from above and lower level executives including headmasters, supervisors, teachers and learners in formal educational settings.

All in all, if the hard-working teachers try their best to apply context-use instruction techniques they would be able to provoke better planning, explicit instruction, enough practice and feedback scaffolding that provokes more responsibility among students.

\section{References}

Anderson, J. (2008). Towards integrated second language teaching pedagogy for foreign and community/ heritage languages in multilingual Britain. Language Learning Journal, 36, 79-89.

Arthur, J., \& Martin, P. (2006). Accomplishing lessons in postcolonial classrooms: Comparative perspectives from Botswana and Brunei Darussalam. Comparative Education, 42, 177-202.

Beck, I. L., \& McKeown, M. G. (1991). Conditions of vocabulary acquisition. In R. Barr, M. Kamil, P. Mosenthal, \& P. D. Pearson (Eds.), Handbook of Reading research (Vol. 2, pp. 789-814). New York: Longman.

Beglar, D., \& Hunt, A. (2002). Implementing task-based language teaching. In J. Richards, \& W. A. Renandya (Eds.), Methodology in language teaching: An anthology of current practice (pp. 96-106). Cambridge: Cambridge University Press.

Christensen, E., Merrill, P., \& Yanchar, S. (2007). Second language vocabulary acquisition using a Diglot reader or a Computer-based drill and practice program. Computer Assisted Language Learning, 20, 67-77.

Craik, F., \& Lockhart, R. (1972). Levels of processing: A framework for memory research. Journal of Verbal Learning and Verbal Behavior, 11, 671- 684.

Cummins, J. (2005). A proposal for action: Strategies for recognizing heritage language competence as a learning resource within the mainstream classroom. Modern Language Journal, 89, 585-592.

Decarrico, J. (2001). Vocabulary learning and teaching. In Celce-Murcia (Ed.), Teaching English as a second or foreign language. Boston: Heinle and Heinle.

Diamond, L., \& Gutlohn, L. (2006). Vocabulary Handbook. Consortium on Reading Excellence, Inc.

Ellis, R. (2000). Task-based research and language pedagogy. Language teaching research, 4(3), 193-220.

Hayati, A. M., \& Mohammadi, M. (2009). Task-based instruction vs. translation method in teaching vocabulary: The case of Iranian secondary school students. Iranian Journal of Language Studies, 3(2), 153-176.

Heller, M. (1999). Linguistic minorities and modernity: A sociolinguistic ethnography. London: Longman.

Hismanoglu, H. S. (2011). Task-based language teaching: what every EFL teacher should do. Procedia Social and Behavioral Sciences, 15, 46-52. Published by Elsevier Ltd. http://dx.doi.org/10.1016/j.sbspro.2011.03.049

Hunt, A., \& Belgar, D. (2005). A framework for developing EFL reading vocabulary. Reading in a Foreign Language, 17(1), 23-59. 
Lawson, J. M., \& Hogben, D. (1996). The vocabulary learning strategies of foreign language students. Language Learning, 46(1), 101-135.

Littlewood, W. (2004). The Task Based Approach: Some Questions and Suggestions. ELT Journal, 58(4), 319-326.

Hulstijn, J. H. (2001). Intentional and incidental second language vocabulary learning: A reappraisal of elaboration, rehearsal and automaticity. In P. Robinson (Ed.), Cognition and second language instruction (pp. 258-286). Cambridge: Cambridge University Press.

Mehrabi, Kh. (2011). Teaching vocabulary through Diglot Weave technique. Roshd Amoozesh Zaban Quarterly, 28(1), Fall, 2011, 78-94.

Mezynski, K. (1983). Issues concerning the acquisition of knowledge: Effects of vocabulary training and reading comprehension. Review of Educational Research, 53, 263-279.

Poulisse, N., \& Schils, E. (1995). The influence of task and proficiency related factors on the use of compensatory strategies: a quantitative analysis. In B. Hardely (Ed.), Lexical issues in language learning. Amsterdam: John Benjamin Publishing Company.

Scot, J. A. (2005). The development of word consciousness and general principles for teaching vocabulary. Annual meeting of the International Reading Association. San Antonio: TX.

Swain, M. (1983). Bilingualism without tears. In M.Clarke, \& J. Handscombe (Eds.), TESOL '82: Pacific perspectives on language learning and teaching (pp. 35-46). Washington, DC: TESOL.

Widdowson, H. G. (1989). Knowledge of language and ability for use. Applied Linguistics, 10, 128-137.

Zimmerman, C. B. (1997). Historical trends in second language vocabulary instruction. In J. Coady, \& T. Huckin (Eds), Second Language Vocabulary Acquisition (pp. 5-19). Cambridge, CUP. 